\title{
InTERFerênCias MÚtuas entre a Cultura do Milho, Espécies Forrageiras e Plantas Daninhas em um Sistema de Consórcio. III - Implicações sobre as Plantas Daninhas ${ }^{1}$
}

\author{
Mutual Interference Among Corn Crop, Forage Species and Weeds under a Consortium System. \\ III - Implications to Weeds
}

SEVERINO, F.J. ${ }^{2}$, CARVALHO, S.J.P. ${ }^{3}$ e CHRISTOFFOLETI, P.J. ${ }^{4}$

\begin{abstract}
RESUMO - O objetivo desta pesquisa foi avaliar as conseqüências da adoção de um sistema de consórcio com culturas forrageiras sobre a infestação e a produção de massa seca e área foliar de três espécies daninhas, na cultura do milho. Os tratamentos resultaram da combinação entre quatro niveis do fator plantas forrageiras (Brachiaria decumbens, Brachiaria brizantha, Panicum maximum e ausência de forrageira) e três níveis do fator plantas daninhas (Ipomoea grandifolia - corda-de-viola, Amaranthus hybridus - caruru-roxo e Digitaria horizontalis - capim-colchão). Durante a condução do experimento foram avaliadas a área foliar, a massa seca e a densidade das plantas daninhas quando submetidas à convivência com a associação do milho e espécies forrageiras. De forma geral, o sistema de produção que envolve a associação de uma cultura forrageira com a cultura do milho reduz a infestação e suprime o crescimento de plantas daninhas no sistema; B. decumbens foi a forrageira que menos reduziu a infestação de plantas daninhas; a espécie $B$. brizantha foi a forrageira mais eficiente em reduzir a infestação de corda-de-viola, mas não suprimiu o crescimento do caruru-roxo; e a forrageira $P$. maximum foi a espécie que mais reduziu o crescimento do caruru-roxo e a área foliar do capim-colchão.
\end{abstract}

Palavras-chave: integração, sistemas de manejo, competição, crescimento.

\begin{abstract}
The objective of this research was to evaluate the consequences of adopting a living mulch system with forage grasses on weed infestation, dry weight and leaf area production of three weed species in corn crop. The treatments resulted from the combination between four levels of grass forage factor (Brachiaria decumbens, Brachiaria brizantha, Panicum maximum, and absence of forage) and three levels of the factor weeds (Ipomoea grandifolia, Amaranthus hybridus, and Digitaria horizontalis). Leaf area, dry weight, and density of weeds submitted to living under the association of corn crop and grass forages were evaluated. In general, the production system involving the association of a forage grass with corn crop reduces infestation and suppresses the growth of the weeds in the system; $\boldsymbol{B}$. decumbens was the forage which least reduced weed infestation; the species B. brizantha was the most efficient forage in reducing I. grandifolia infestation, but it did not suppress A. hybridus growth; the forage $\boldsymbol{P}$. maximum was the species that most reduced A. hybridus growth and D. horizontalis leaf area.
\end{abstract}

Keywords: intercrop, management systems, competition, growth.

1 Recebido para publicação em 4.5.2005 e na forma revisada em 24.2.2006.

Parte da tese do primeiro autor apresentada à ESALQ para obtenção do título de Doutor em Agronomia.

2 Eng.-Agr., D.S., Coordenadoria de Assistência Técnica Integral - CATI. ${ }^{3}$ Eng.-Agr., aluno do Programa de Pós-Graduação em Fitotecnia - ESALQ/USP, <sjpcarvalho@yahoo.com.br>; ${ }^{4}$ Professor Associado do Departamento de Produção Vegetal ESALQ/USP, Caixa Postal 9, 13419-900 Piracicaba, SP, <pjchrist@esalq.usp.br>. 


\section{INTRODUÇÃO}

Entre os fatores bióticos que reduzem o rendimento das culturas encontram-se as plantas daninhas, as quais podem afetar a produção econômica, principalmente, em decorrência das interferências negativas impostas por sua presença (Abdin et al., 2000; Pitelli, 1985). De maneira geral, as plantas daninhas interferem no desenvolvimento das plantas de milho com intensidade variável, em função da época de ocorrência, da densidade populacional e das espécies presentes no local (Zagonel et al., 2000).

Inicialmente, o manejo mais comum de plantas daninhas nas culturas agrícolas envolvia a adoção de capina manual e cultivo mecânico nas entrelinhas, com reconhecida eficiência (Abdin et al., 2000; Wilson, 1993). Posteriormente, devido ao desenvolvimento dos métodos químicos, a aplicação de herbicidas tornou-se a medida de manejo adotada com maior freqüência, sobretudo em conseqüência de sua eficácia, conveniência e viabilidade de custos (Abdin et al., 2000; Jakelaitis et al., 2005). No entanto, essas medidas, quando utilizadas isoladamente, podem não ser suficientes para eliminar toda a interferência das plantas daninhas nas culturas, exigindo medidas integradas de manejo.

As inovações tecnológicas para o controle de plantas daninhas na cultura do milho contemplam: conhecimento da dinâmica do banco de sementes que sustenta o abastecimento populacional de plantas daninhas; aplicação de herbicidas em condições de pós-emergência; utilização de herbicidas juntamente com outros defensivos; integração da cultura do milho com a produção de forrageiras; e necessidade do produtor em adotar medidas alternativas de controle das plantas daninhas (Christoffoleti \& Mendonça, 2001).

A rotação de culturas, incluindo o emprego de espécies de cobertura vegetal, é uma alternativa de manejo que propicia diferentes modelos de competição, alelopatia e distúrbios do solo em cada uma das culturas seqüenciadas, reduzindo, assim, o banco de sementes e a pressão de seleção sobre plantas daninhas específicas (Buhler et al., 1997; Anderson, 2004). Nesse sentido, a consorciação da cultura do milho com plantas forrageiras se apresenta como uma prática eficiente de supressão de plantas daninhas (De Haan et al., 1994; Teasdale, 1996).

A cobertura vegetal viva que permanece no solo durante o desenvolvimento da cultura principal pode ocasionar competição direta pelos recursos de crescimento (luz, água e nutrientes), fato que, possivelmente, representa a principal forma de supressão das plantas daninhas (Teasdale, 1993; Mayer \& Hartwig, 1986). A presença do material vegetal sobre o solo, vivo ou não, pode inibir a germinação e o estabelecimento de plantas daninhas com muito mais eficiência do que os resíduos dessecados de culturas.

Pesquisas realizadas com espécies forrageiras têm mostrado significativas reduções nas populações de plantas daninhas em alguns sistemas de produção (Hartwig, 1989; Enache \& Ilnicki, 1990). Por outro lado, mesmo a melhor das espécies perenes mostra falhas no seu crescimento ou na ocupação de todos os nichos ecológicos. Dessa maneira, sempre há alguma diversidade de espécies, onde as plantas daninhas com fenologia e morfologia compatíveis com a espécie utilizada como cobertura vegetal podem se tornar infestantes da área (Severino, 2000).

Dessa maneira, embora as forrageiras possam ser ferramentas efetivas para o controle de plantas daninhas, elas requerem manejo compativel, particularmente para prevenir a invasão e o estabelecimento de novas espécies ao longo do tempo (Severino, 2000). Assim, o objetivo desta pesquisa foi avaliar as conseqüências da adoção de um sistema de consórcio entre a cultura do milho e plantas forrageiras sobre a infestação, o crescimento e a conseqüente produção de massa seca e área foliar por plantas daninhas.

\section{MATERIAL E MÉTODOS}

O experimento foi conduzido em área experimental pertencente ao Departamento de Produção Vegetal da ESALQ/USP, em Piracicaba-SP (2242’30”' latitude sul, 47³0' longitude oeste e $546 \mathrm{~m}$ de altitude), durante o período compreendido entre os meses de dezembro de 2003 e maio de 2004. O solo da área experimental foi classificado como Nitossolo Vermelho (eutroférrico chernossólico) 
(Embrapa, 1999) e suas propriedades químicas estão apresentadas na Tabela 1 .

O clima da região é do tipo 'Cwa' (Köppen, 1948), isto é, mesotérmico, tropical úmido, com três meses mais secos (junho, julho e agosto) e concentração de chuvas no verão. A temperatura média do mês mais quente é superior a $24{ }^{\circ} \mathrm{C}$, e a do mês mais frio, inferior a $17^{\circ} \mathrm{C}$, apresentando pluviosidade média anual de $1.200 \mathrm{~mm}$.

O delineamento experimental adotado foi o de blocos casualizados, em esquema de parcelas subdivididas, utilizando-se três repetições. Os tratamentos resultaram das combinações entre quatro níveis do fator culturas forrageiras, alocadas nas subparcelas (Brachiaria decumbens - capim-braquiária, Brachiaria brizantha - capim-braquiarão, Panicum maximum - capim-colonião e ausência de planta forrageira), e três níveis do fator plantas daninhas, alocadas nas parcelas (Ipomoea grandifolia - corda-de-viola, Amaranthus hybridus - caururu-roxo e Digitaria horizontalis- - capim-colchão), sempre na presença da cultura do milho.

Cada subparcela constou de cinco linhas de milho, intercaladas com quatro linhas das respectivas culturas forrageiras, com $2,0 \mathrm{~m}$ de comprimento cada; portanto, uma área útil total de $7,2 \mathrm{~m}^{2}$ (3,6 $\left.\times 2 \mathrm{~m}\right)$. O solo foi preparado através de roçagem, seguida de gradagem na profundidade de $0,20 \mathrm{~m}$, uma escarificação na profundidade aproximada de $0,30 \mathrm{~m}$ e uma gradagem niveladora na profundidade média de $0,10 \mathrm{~m}$. Foi realizada uma adubação na semeadura nas doses de 30,4, 106,4 e $60,8 \mathrm{~kg} \mathrm{ha}^{-1}$ de $\mathrm{N}, \mathrm{P}_{2} \mathrm{O}_{5}$ e $\mathrm{K}_{2} \mathrm{O}$, respectivamente, e uma aplicação de nitrogênio em cobertura, aos 40 dias após a semeadura, na dose de $60 \mathrm{~kg} \mathrm{ha}^{-1}$.

A cultura do milho foi semeada em linhas, com semeadora tratorizada, em espaçamento de 0,90 m entre linhas e densidade de oito sementes por metro linear, a qual permitiu uma população média de 80.000 plantas ha ${ }^{-1}$, com base nos parâmetros do valor cultural da semente utilizada. O material genético de milho utilizado foi o cultivar CATI AL 34, sendo as sementes tratadas com o fungicida ftalimida na concentração de $0,75 \mathrm{~g} \mathrm{~kg}^{-1}$ de sementes. A semeadura das forrageiras foi feita no mesmo dia da do milho e realizada manualmente entre as linhas da cultura, com sementes adquiridas comercialmente, cujos índices de germinação e vigor informado foram utilizados almejando-se a produção média homogênea de $50.000 \mathrm{~kg} \mathrm{ha}^{-1}$ de massa fresca para as três forrageiras.

A semeadura das plantas daninhas cordade-viola e caruru-roxo foi feita a lanço, seguida de incorporação com enxada, enquanto a planta daninha capim-colchão fazia parte da vegetação espontânea da área. A quantidade de sementes de caruru-roxo e corda-de-viola distribuídas por parcela baseou-se em testes prévios de emergência das sementes no campo, cujos resultados foram fornecidos pela empresa onde estas mesmas foram adquiridas, de maneira a resultar em aproximadamente 50 plantas $\mathrm{m}^{-2}$ na testemunha. Nas parcelas onde não eram desejados, o capim-colchão e as outras plantas daninhas não semeadas foram suprimidos pelas plantas semeadas (milho, forrageira e planta daninha) e, portanto, não interferiram nos resultados experimentais.

As avaliações realizadas durante a condução do ensaio foram: infestação das espécies daninhas, por meio da densidade (plantas $\mathrm{m}^{-2}$ ), aos 30 e 60 dias após a instalação do experimento; massa seca (g por planta); e área foliar $\left(\mathrm{cm}^{2}\right.$ por planta). A densidade das plantas daninhas foi avaliada com o uso de um gabarito de madeira quadrado, medindo $0,5 \mathrm{~m}^{2}$, com duas amostragens ao acaso nas subparcelas.

Tabela 1 - Propriedades químicas do solo da área experimental. Piracicaba-SP, 2004

\begin{tabular}{|c|c|c|c|c|c|c|c|c|c|c|}
\hline $\mathrm{pH}$ & M.O. & $\mathrm{P}($ resina $)$ & $\mathrm{S}$ & $\mathrm{K}$ & $\mathrm{Ca}$ & $\mathrm{Mg}$ & $\mathrm{H}+\mathrm{Al}$ & $\mathrm{SB}$ & $\mathrm{CTC}$ & $\mathrm{V}$ \\
\hline$\left(\mathrm{CaCl}_{2}\right)$ & $\left(\mathrm{g} \mathrm{dm}^{-3}\right)$ & \multicolumn{2}{|c|}{$\left(\mathrm{mg} \mathrm{dm}^{-3}\right)$} & \multicolumn{6}{|c|}{$\left(\mathrm{mmol}_{\mathrm{c}} \mathrm{dm}^{-3}\right)$} & $(\%)$ \\
\hline 5,1 & 19 & 13 & 57 & 3,8 & 40 & 12 & 28 & 55,8 & 83,7 & 67 \\
\hline
\end{tabular}

Amostra analisada no Laboratório de Análises de Solo da ESALQ/USP. 
As avaliações de massa seca e área foliar foram feitas através da colheita de três plantas em cada subparcela, ao acaso, cortadas na superfície do solo, sendo a área foliar avaliada imediatamente após o corte, através do equipamento LICOR - LI 7000, de acordo com metodologia proposta por Benincasa (2003). O material colhido foi colocado em sacos de papel, secado em estufa a $50{ }^{\circ} \mathrm{C}$ durante 72 horas e, posteriormente, pesado. Os resultados utilizados na discussão representam médias das três plantas avaliadas. As avaliações foram realizadas em intervalos de 14 dias, iniciando-se aos 14 dias após a semeadura do milho, totalizando 12 avaliações.

Os dados de densidade das plantas daninhas foram inicialmente transformados segundo o modelo $\sqrt{\mathrm{x \square 0,5}}$, para satisfazer a necessidade de distribuição normal dos resultados. Em seguida, a variável foi analisada através da aplicação do teste $\mathrm{F}$ sobre a análise da variância, seguida do teste Tukey a 5\% de significância, para comparação das médias das interações significativas.

Os resultados da área foliar e massa seca das plantas foram analisados por meio de regressões não-lineares, segundo modelo loglogístico proposto por Seefeldt et al. (1995):

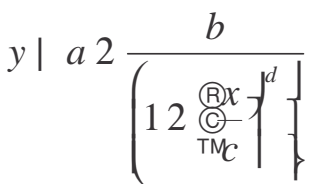

em que $y=$ variável resposta; $x=$ tempo (dias) após a semeadura do milho; $a=$ ponto mínimo da curva; $b=$ diferença entre o ponto máximo e o ponto mínimo; $c=$ tempo em dias necessário para que ocorra $50 \%$ de resposta da variável; e $d=$ declividade da curva.

\section{RESULTADOS E DISCUSSÃO}

Nas Tabelas 2 e 3, pode-se observar que, de modo geral, as três culturas forrageiras testadas, juntamente com os efeitos promovidos pela cultura do milho, suprimiram a densidade das plantas daninhas do experimento, exceto Brachiaria decumbens para corda-de-viola, cuja infestação não diferenciou da testemunha. O melhor resultado na supressão da cordade-viola foi obtido com a espécie $B$. brizantha.
A testemunha apresentou diferenças de densidade entre as três espécies de plantas daninhas, fato que pode estar relacionado com a interferência exclusiva da cultura do milho sobre a germinação destas plantas. Corda-deviola manteve a maior densidade quando comparada com caruru-roxo e capim-colchão, nas condições de consórcio com P. maximume B. decumbens (Tabela 1). A competitividade da corda-de-viola pode estar relacionada com o hábito de crescimento do tipo trepador. Este hábito de crescimento condiciona a espécie a um nicho ecológico diferenciado, em que as plantas estão menos expostas à competição por luz.

A redução da infestação das plantas daninhas pode ser atribuída aos efeitos competitivos e/ou alelopáticos. Espécies forrageiras possuem características vantajosas no que diz respeito à utilização dos recursos disponíveis no ambiente (Nicholson \& Wien, 1983; Chou et al., 1989; Dias Filho, 2000). Essas

Tabela 2 - Densidade de plantas daninhas $\left(\right.$ plantas $\mathrm{m}^{-2}$ ) na interação entre tratamentos com culturas forrageiras e plantas daninhas, na cultura do milho, aos 30 dias após a instalação do experimento. Piracicaba-SP, 2004

\begin{tabular}{|c|c|c|c|}
\hline \multirow{2}{*}{ Cultura forrageira } & \multicolumn{3}{|c|}{ Densidade de plantas daninhas } \\
\hline & Corda-de-viola & Caruru-roxo & Capim-colchão \\
\hline Brachiaria decumbens & $28,5^{2 /} \mathrm{aB}$ & $16,9 \mathrm{bB}$ & $5,5 \mathrm{bC}$ \\
\hline Brachiaria brizantha & $2,3 \mathrm{cAB}$ & $6,6 \mathrm{cA}$ & $1,9 \mathrm{bB}$ \\
\hline Panicum maximum & $11,2 \mathrm{bA}$ & $2,5 \mathrm{cB}$ & $4,9 \mathrm{bB}$ \\
\hline Testemunha $\mathrm{a}^{1 /}$ & $41,2 \mathrm{aB}$ & $71,7 \mathrm{aA}$ & $32,4 \mathrm{aC}$ \\
\hline $\mathrm{CV} \%{ }^{3 / 1}$ & \multicolumn{3}{|c|}{14,77} \\
\hline
\end{tabular}

1/ Testemunha sem capina; ${ }^{2}$ Médias seguidas por letras distintas, maiúsculas na linha e minúsculas na coluna, diferem entre si a $5 \%$ de significância pelo teste de Tukey; ${ }^{3 /}$ Coeficiente de variação.

Tabela 3 - Densidade de plantas daninhas (plantas $\mathrm{m}^{-2}$ ) na interação entre tratamentos com culturas forrageiras e plantas daninhas, na cultura do milho, aos 60 dias após a instalação do experimento. Piracicaba-SP, 2004

\begin{tabular}{|l|c|c|c|}
\hline \multirow{2}{*}{ Cultura forrageira } & \multicolumn{3}{|c|}{ Densidade de plantas daninhas } \\
\cline { 2 - 4 } & Corda-de-viola & Caruru-roxo & Capim-colchão \\
\hline Brachiaria decumbens & $33,5^{2 /} \mathrm{aA}$ & $18,8 \mathrm{bB}$ & $5,6 \mathrm{bC}$ \\
\hline Brachiaria brizantha & $3,6 \mathrm{cA}$ & $4,3 \mathrm{cA}$ & $3,4 \mathrm{bA}$ \\
\hline Panicum maximum & $12,4 \mathrm{bA}$ & $3,6 \mathrm{cB}$ & $4,3 \mathrm{bB}$ \\
\hline Testemunha $^{\mathrm{I}}$ & $36,3 \mathrm{aB}$ & $72,2 \mathrm{aA}$ & $37,3 \mathrm{aB}$ \\
\hline $\mathrm{CV}^{3 / 1}$ & \multicolumn{3}{|c|}{13,08} \\
\hline
\end{tabular}

1/ Testemunha sem capina; 느 Médias seguidas por letras distintas, maiúsculas na linha e minúsculas na coluna, diferem entre si a $5 \%$ de significância pelo teste de Tukey; ${ }^{3 /}$ Coeficiente de variação. 
características de potencial competitivo são essenciais quanto ao uso de forrageiras como estratégias ecológicas de manejo de plantas daninhas (Nicholson \& Wien, 1983; Enache \& Ilnicki, 1990; DeHaan et al., 1994).

Nas Tabelas 4 e 5 são apresentados os parâmetros estimados do modelo logístico para as variáveis acúmulo de massa seca e área foliar durante o crescimento das plantas daninhas na presença da cultura do milho, em função das culturas forrageiras. Esses parâmetros possibilitam a adequação das equações do modelo logístico que foi utilizado para elaboração dos gráficos, de ambas as variáveis, apresentados nas Figuras 1 a 3.

Tabela 4 - Parâmetros estimados do modelo logístico ${ }^{1 /}$ e coeficiente de determinação $\left(\mathrm{R}^{2}\right)$ para a variável acúmulo de massa seca (g por planta) durante o crescimento das espécies daninhas na presença da cultura do milho e das culturas forrageiras. Piracicaba-SP, 2004

\begin{tabular}{|c|c|c|c|c|c|c|}
\hline \multirow{2}{*}{\multicolumn{2}{|c|}{ Tratamento }} & \multicolumn{4}{|c|}{ Parâmetro } & \multirow{3}{*}{$\begin{array}{c}\mathrm{R}^{2} \\
0,997\end{array}$} \\
\hline & & \multirow{2}{*}{$\frac{\mathrm{a}}{9,636}$} & \multirow{2}{*}{$\frac{b}{-9,289}$} & \multirow{2}{*}{$\frac{c}{54,453}$} & \multirow{2}{*}{$\frac{\mathrm{d}}{11,143}$} & \\
\hline \multirow{3}{*}{ Brachiaria decumbens } & Corda-de-viola & & & & & \\
\hline & Caruru-roxo & 0,783 & 14,971 & 68,639 & $-7,762$ & 0,980 \\
\hline & Capim-colchão & 0,394 & 17,685 & 73,236 & $-8,901$ & 0,998 \\
\hline \multirow{3}{*}{ Brachiaria brizantha } & Corda-de-viola & 0,386 & 9,513 & 56,927 & $-16,936$ & 0,995 \\
\hline & Caruru-roxo & 1,242 & 18,300 & 79,006 & $-7,903$ & 0,978 \\
\hline & Capim-colchão & 0,469 & 17,788 & 74,933 & $-9,493$ & 0,996 \\
\hline \multirow{3}{*}{ Panicum maximum } & Corda-de-viola & 0,148 & 9,726 & 54,453 & $-9,203$ & 0,998 \\
\hline & Caruru-roxo & 0,536 & 12,759 & 61,811 & $-6,171$ & 0,983 \\
\hline & Capim-colchão & 0,368 & 18,341 & 73,558 & $-9,164$ & 0,999 \\
\hline \multirow{3}{*}{ Testemunha $a^{2 /}$} & Corda-de-viola & 0,688 & 20,630 & 71,329 & $-5,934$ & 0,986 \\
\hline & Caruru-roxo & 1,115 & 18,500 & 58,025 & $-13,464$ & 0,988 \\
\hline & Capim-colchão & 0,207 & 23,023 & 68,538 & $-5,764$ & 0,996 \\
\hline
\end{tabular}

${ }^{1 /}$ Modelo: $y=a+\left(b /\left(1+(x / c)^{d}\right)\right) .{ }^{2 /}$ Testemunha = espécie daninha crescendo sem a presença das culturas forrageiras.

Tabela 5 - Parâmetros estimados do modelo logístico ${ }^{1 /}$ e coeficiente de determinação $\left(\mathrm{R}^{2}\right)$ para a variável acúmulo de área foliar $\left(\mathrm{cm}^{2}\right.$ por planta) durante o crescimento das espécies daninhas na presença da cultura do milho e das culturas forrageiras. Piracicaba-SP, 2004

\begin{tabular}{|c|c|c|c|c|c|c|}
\hline \multirow{2}{*}{\multicolumn{2}{|c|}{ Tratamento }} & \multicolumn{4}{|c|}{ Parâmetro } & \multirow{3}{*}{$\frac{\mathrm{R}^{2}}{0,991}$} \\
\hline & & \multirow{2}{*}{$\frac{\mathrm{a}}{1,893}$} & \multirow{2}{*}{$\frac{b}{499,137}$} & \multirow{2}{*}{$\frac{c}{49,747}$} & \multirow{2}{*}{$\frac{d}{-3,326}$} & \\
\hline \multirow{3}{*}{ Brachiaria decumbens } & Corda-de-viola & & & & & \\
\hline & Caruru-roxo & $-15,055$ & 539,459 & 74,214 & $-1,466$ & 0,927 \\
\hline & Capim-colchão & 28,281 & 401,811 & 73,684 & $-4,703$ & 0,971 \\
\hline \multirow{3}{*}{ Brachiaria brizantha } & Corda-de-viola & 11,461 & 463,734 & 50,023 & $-4,703$ & 0,990 \\
\hline & Caruru-roxo & $-6,007$ & 468,330 & 56,044 & $-2,145$ & 0,984 \\
\hline & Capim-colchão & 24,257 & 423,358 & 73,904 & $-3,484$ & 0,948 \\
\hline \multirow{3}{*}{ Panicum maximum } & Corda-de-viola & 35,134 & 410,958 & 46,808 & $-9,323$ & 0,986 \\
\hline & Caruru-roxo & 7,124 & 458,215 & 93,133 & $-1,162$ & 0,951 \\
\hline & Capim-colchão & 9,660 & 609,906 & 115,050 & $-2,319$ & 0,959 \\
\hline \multirow{3}{*}{ Testemunha ${ }^{\underline{2} /}$} & Corda-de-viola & 17,053 & $1.093,485$ & 74,094 & $-2,675$ & 0,972 \\
\hline & Caruru-roxo & 12,022 & 417,156 & 47,565 & $-5,573$ & 0,983 \\
\hline & Capim-colchão & 2,535 & 509,070 & 56,646 & $-2,758$ & 0,995 \\
\hline
\end{tabular}

${ }^{1 /}$ Modelo: $\mathrm{y}=\mathrm{a}+\left(\mathrm{b} /\left(1+(\mathrm{x} / \mathrm{c})^{\mathrm{d}}\right)\right) .{ }^{2 /}$ Testemunha = espécie daninha crescendo sem a presença das culturas forrageiras. 

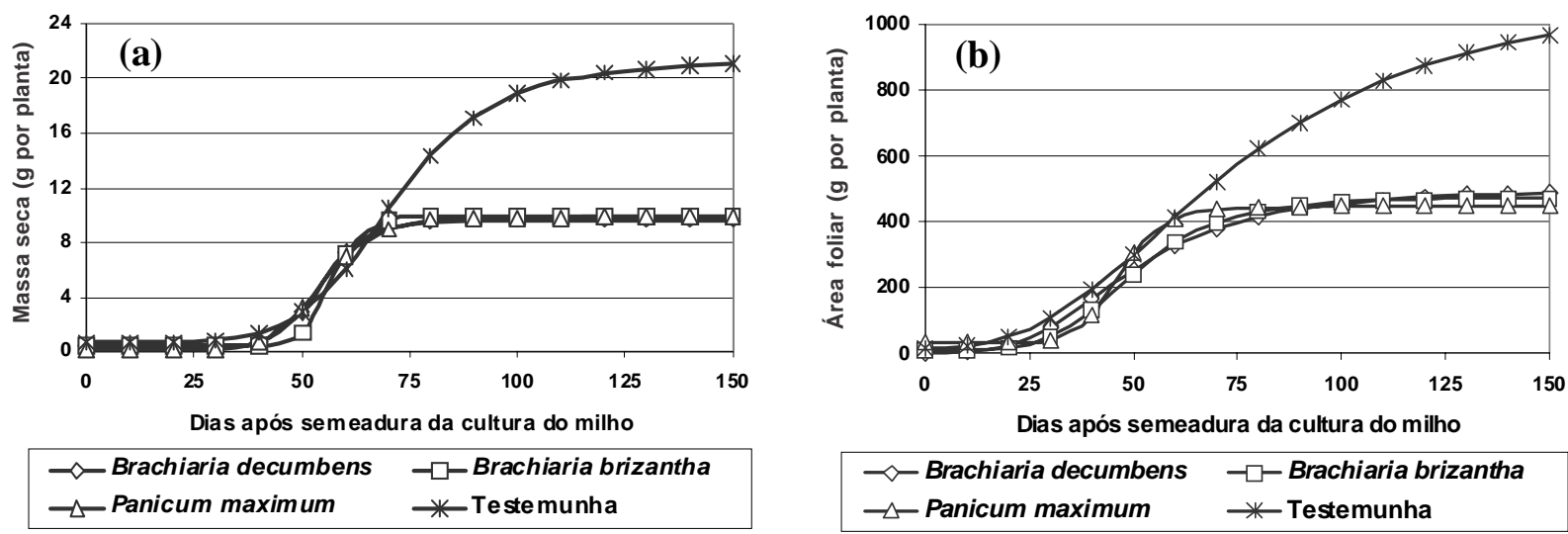

\begin{tabular}{ll|}
$\neg$ Brachiaria decumbens & $-\square-$ Brachiaria brizantha \\
$\neg-$ Panicum maximum & $\rightarrow$ Testemunha
\end{tabular}

Figura 1 - Acúmulo de massa seca (a) e área foliar (b) pela planta daninha corda-de-viola (Ipomoea grandifolia) quando na presença da cultura do milho e das culturas forrageiras e sem a presença destas (testemunha). Piracicaba-SP, 2004.
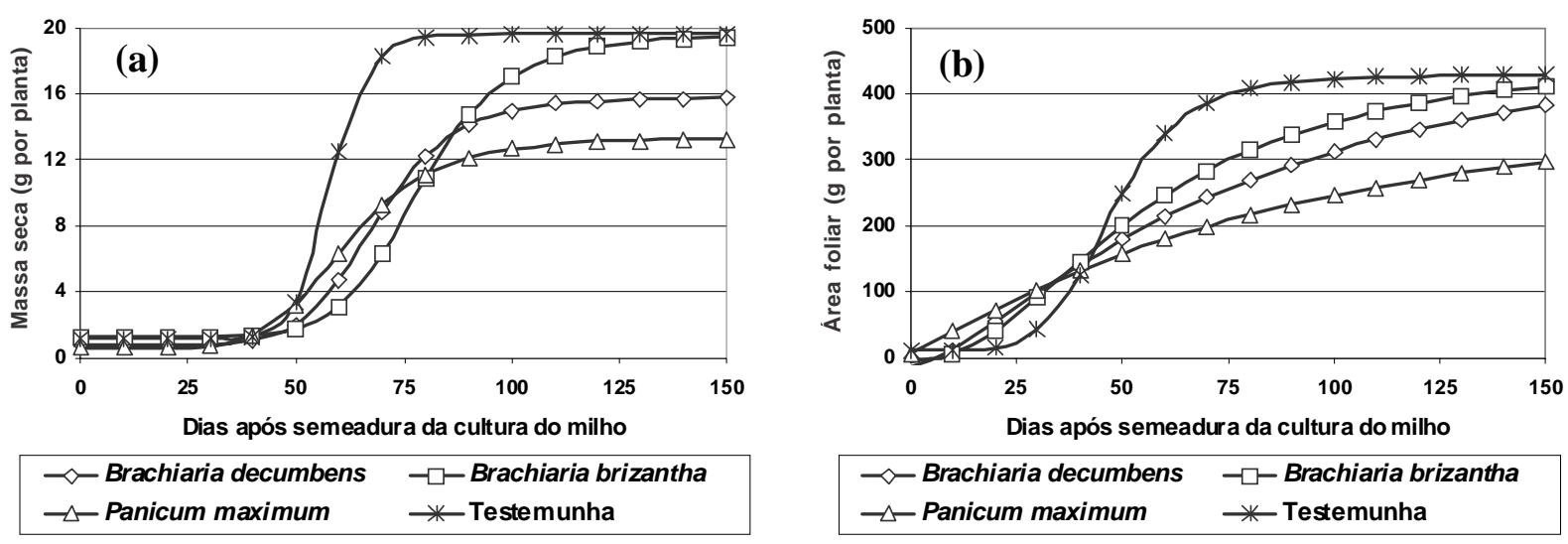

\begin{tabular}{ll|}
$\neg$ Brachiaria decumbens & $-\square-$ Brachiaria brizantha \\
$\neg-$ Panicum maximum & $\rightarrow$ Testemunha
\end{tabular}

Figura 2 - Acúmulo de massa seca (a) e área foliar (b) pela planta daninha caruru-roxo (Amaranthus hybridus) quando na presença da cultura do milho e das culturas forrageiras e sem a presença destas (testemunha). Piracicaba-SP, 2004.
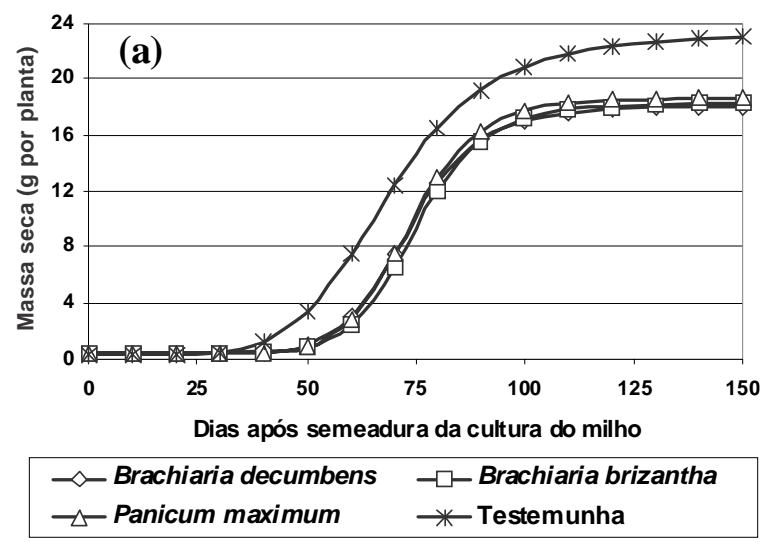
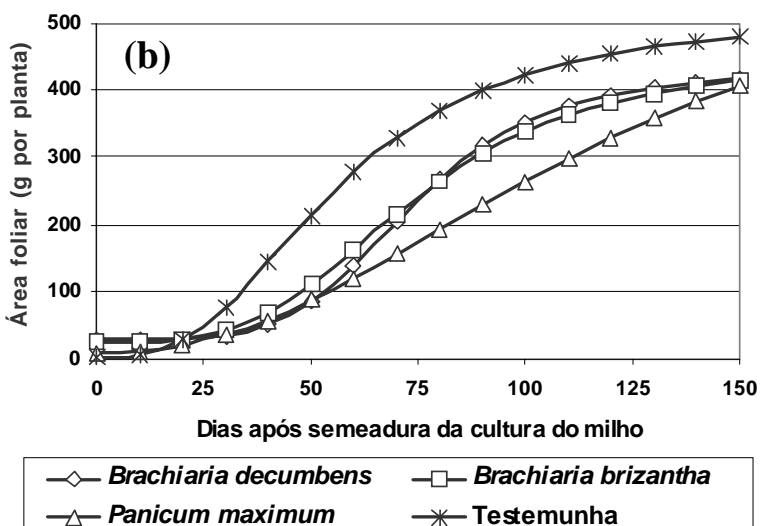

Figura 3 - Acúmulo de massa seca (a) e área foliar (b) pela planta daninha capim-colchão (Digitaria horizontalis) quando na presença da cultura do milho e das culturas forrageiras e sem a presença destas (testemunha). Piracicaba-SP, 2004. 
Na Figura 1, observa-se que a produção de massa seca (a) e área foliar (b) pelas plantas de corda-de-viola foram suprimidas de forma semelhante pelas três culturas forrageiras consorciadas com a cultura do milho, principalmente a partir dos 70 dias, aproximadamente, quando comparada com a curva obtida para o tratamento sem as forrageiras. A variável massa seca apresentou padrão de resposta semelhante ao mostrado pela variável área foliar.

Na Figura 2, verifica-se que o caruru-roxo teve sua produção de massa seca (a) e área foliar (b) inibida pelos três tratamentos com as culturas forrageiras na presença do milho, quando comparada com o tratamento da planta daninha crescendo isoladamente, a partir do qüinquagésimo até o octogésimo dia, aproximadamente. No entanto, observa-se que houve supressão diferencial desta planta daninha pelas culturas forrageiras, uma vez que $P$. maximum foi mais efetivo nessa supressão, seguido de $B$. decumbens. Já $B$. brizantha proporcionou o menor efeito supressivo, tanto que ao final do ciclo da planta daninha o acúmulo de massa seca e o de área foliar igualaram-se ao total do tratamento, onde o caruru-roxo cresceu somente na presença do milho.

Para a planta daninha capim-colchão (Figura 3), todas as culturas forrageiras, em convivência com a cultura do milho, exerceram efeito supressivo semelhante sobre o acúmulo de massa seca (a), porém de forma menos intensa do que para a planta daninha corda-de-viola. No caso do acúmulo de área foliar (b), P. maximum foi mais eficiente que as demais forrageiras durante boa parte do ciclo, igualando-se a estas próximo do final. Acredita-se que a coexistência em um agroecossistema de plantas que apresentam fisiologia de crescimento semelhantes condiciona relações competitivas interespecíficas mais intensas (Willey, 1979), fato que pode explicar, em parte, esses resultados alcançados.

Outro aspecto que deve ser mencionado é que, possivelmente, o fato de a semeadura da cultura do milho e das forrageiras ter sido realizada no mesmo dia conferiu às plantas forrageiras maior capacidade de supressão das plantas daninhas, provavelmente em conseqüência da rápida ocupação do nicho ecológico.
Conseqüentemente, elas diminuíram os recursos necessários ao crescimento e desenvolvimento das plantas daninhas. A situação observada neste experimento corrobora resultados mencionados por Radosevich (1996) e Silva et al. (2004).

Assim, pode-se concluir que: o sistema de produção que envolve a semeadura de uma cultura forrageira em consórcio com a cultura do milho, em geral, reduz a infestação e suprime o acúmulo de massa seca e área foliar de plantas daninhas no sistema; Brachiaria decumbens foi a forrageira que menos reduziu a infestação de plantas daninhas; Brachiaria brizantha foi a forrageira mais eficiente em diminuir a infestação de corda-de-viola e menos eficiente em suprimir o crescimento do caruru-roxo; a planta forrageira Panicum maximum, por sua vez, reduziu o crescimento do caruru-roxo e a área foliar do capim-colchão.

\section{LITERATURA CITADA}

ABDIN, O. A. et al. Cover crops and interrow tillage for weed control in short season maize (Zea mays). Eur. J. Agron., v. 12, p. 93-102, 2000.

ANDERSON, R. L. Sequencing crops to minimize selection pressure for weeds in the Central Great Plains. Weed Technol., v. 18, p. 157-164, 2004.

BENINCASA, M. M. P. Análise de crescimento de plantas: noções básicas. 2.ed. Jaboticabal: UNESP/ FUNEP, 2003. $41 \mathrm{p}$.

BUHLER, D. D.; HARTZLER, R. G.; FORCELLA, F. Implications of weed seedbank dynamics to weed management. Weed Sci., v. 45, p. 329-336, 1997.

CHOU, C. H. et al. The selective allelophatic interaction of pasture-forest intercropping in Taiwan. II. Interaction between kikuyu-grass and three hardwood plants. Plant Soil, v. 116, p. 207-215, 1989.

CHRISTOFFOLETI, P. J.; MENDONÇA, C. G. Controle de plantas daninhas na cultura de milho: enfoque atual. In: FANCELLI, A.L.; DOURADO NETO, D. Milho: tecnologia e produtividade. Piracicaba: ESALQ/LPV, 2001. $259 \mathrm{p}$.

DE HAAN, R. L. et al. Simulation of spring-seeded smoother plants for weed control in corn (Zea mays). Weed Sci., v. 42, p. 35-43, 1994.

Planta Daninha, Viçosa-MG, v. 24, n. 1, p. 53-60, 2006 
DIAS FILHO, M. B. Growth and biomass allocation of the $\mathrm{C}_{4}$ grasses Brachiaria brizantha and Brachiaria humidicola under shade. Pesq. Agropec. Bras., v. 35, p. 2335-2341, 2000.

EMPRESA BRASILEIRA DE PESQUISA

AGROPECUÁRIA - EMBRAPA. Sistema brasileiro de classificação de solos. Brasília: 1999. 412 p.

ENACHE, A. J.; ILNICKI, R. D. Weed control by subterranean clover used as living mulch. Weed Technol., v. 4, p. 534-538, 1990.

HARTWIG, N. L. Influence of crownvetch living mulch on dandelion invasion in corn. Proc. Northeast. Weed Sci. Soc., v. 33, p. 25-28, 1989.

JAKELAITIS, A. et al. Efeitos de herbicidas no consórcio de milho com Brachiaria brizantha. Planta Daninha, v. 23, p. 69-78, 2005.

KÖPPEN, W. Climatologia: con un estudio de los climas de la tierra. México: Fondo de Cultura Económica, 1948. 478 p.

MAYER, J. B.; HARTWIG, N. L. Corn yield in crownvetch relative to dead mulches. Proc. Northeast. Weed Sci. Soc., v. 40, p. 34-35, 1986.

NICHOLSON, A. G.; WIEN, H. C. Screening of turfgrasses and clovers for use as living mulches in sweet corn and cabbage. J. Am. Soc. Hort. Sci., v. 108, p. 1071-1076, 1983.

PITELLI, R. A. Interferências de plantas daninhas em culturas agrícolas. Inf. Agropec., v. 11, p. 16-27, 1985.

RADOSEVICH, S. Physiological aspects of competition. In: RADOSEVICH, S. Weed ecology. 2.ed. New York: Willey, 1996. p. 217-301.
SEEFELDT, S. S.; JENSEN, J. E.; FUERST, E. P. Loglogistic analysis of herbicide dose-response relationship. Weed Technol., v. 9, p. 218-227, 1995.

SEVERINO, F. J. Efeitos de diferentes adubos verdes na supressão de plantas daninhas e seletividade de herbicidas. 2000. 120 f. Dissertação (Mestrado em Agronomia) - Escola Superior de Agricultura "Luiz de Queiroz", Piracicaba, 2000.

SILVA, A. A.; JAKELAITIS, A.; FERREIRA, L. R. Manejo de plantas daninhas no sistema integrado agricultura-pecuária. In: ZAMBOLIM, L.; SILVA, A. A.; AGNES, E. L. Manejo integrado: integração agricultura-pecuária. Viçosa: 2004. p. 117-170.

TEASDALE, J. R. Contribution of cover crops to weed management in sustainable agricultural systems. J. Prod. Agric., v. 9, p. 475-479, 1996.

TEASDALE, J. R. Reduced-herbicide weed management systems for no-tillage corn (Zea mays) in a hairy vetch (Vicia villosa) cover crop. Weed Technol., v. 7, p. 879-883, 1993.

WILLEY, R. W. Intercropping: its importance and research needs. Part. 1. Competition and yield advantages. Field Crop. Abst., v. 42, p. 1-10, 1979.

WILSON, R. G. Effect of preplant tillage, post-plant cultivation and herbicides on weed density in corn. Weed Technol., v. 7, p. 728-734, 1993.

ZAGONEL, J.; VENÂNCIO, W. S.; KUNZ, R. P. Efeitos de métodos e épocas de controle das plantas daninhas na cultura do milho. Planta Daninha, v. 18, p. 143-150, 2000 . 